\title{
Guia de fontes: grafia da etnia, autores e obras ${ }^{1}$
}

\begin{tabular}{|c|c|c|c|c|c|}
\hline $\begin{array}{l}\text { Década/total } \\
\text { trabalhos }\end{array}$ & $\begin{array}{l}\text { Grafia } \\
\text { etnia }\end{array}$ & autor & Título do trabalho & $\begin{array}{l}\text { Outros dados } \\
\text { bibliográficos }\end{array}$ & Ano \\
\hline $\begin{array}{c}1900 \text { a } 1909 \\
1\end{array}$ & Cachuanas & $\begin{array}{l}\text { Coudreau, } \\
\text { Olga }\end{array}$ & $\begin{array}{l}\text { Voyage au Trombetas } \\
7 \text { aout } 1899-25 \text { novembre } \\
1899\end{array}$ & $\begin{array}{l}\text { Lahure, Imprimeur-éditeur, } \\
\text { Paris }\end{array}$ & 1900 \\
\hline 1910 a 1919 & \multicolumn{5}{|c|}{ Nada encontrado } \\
\hline $\begin{array}{c}1920 \text { a } 1929 \\
1\end{array}$ & Caxuianá & $?$ & $\begin{array}{l}\text { Relatório dos Trabalhos } \\
\text { Ethnographicos - A Ex- } \\
\text { pedição; a Tribu do rio } \\
\text { Cachorro }\end{array}$ & $\begin{array}{l}\text { Relatório datilografado, } \\
\text { incompleto. Arquivo } \\
\text { Semear/Museu Nacional } \\
\text { (fotocópia do original } \\
\text { destruído pelo incêndio do } \\
\text { Museu Nacional) }\end{array}$ & $1929(?)$ \\
\hline \multirow[t]{2}{*}{$\begin{array}{c}1930 \text { a } 1939 \\
2\end{array}$} & & Hurley, Jorge & $\begin{array}{l}\text { Vocabulário dos aboríge- } \\
\text { nes dos rios Trombetas, } \\
\text { Cachorro e Jacycury }\end{array}$ & $\begin{array}{l}\text { Revista do Instituto Histó- } \\
\text { rico e Geográfico do Pará } \\
\text { 7: 229-235 }\end{array}$ & 1932 \\
\hline & Kaciana & Kruse, Albert & $\begin{array}{l}\text { Etwas Von den Kaciana } \\
\text { (Sobre os índios Kaciana. } \\
\text { Trad. Ingrid Lenk) }\end{array}$ & $\begin{array}{l}\text { Lose Blätter von Cururu, } \\
\text { Santo Antonio, Provinz- } \\
\text { zeitschrift der Franziska- } \\
\text { nen in Nord Brasilien } 2\end{array}$ & 1933 \\
\hline \multirow[t]{2}{*}{3} & & $\begin{array}{l}\text { Aguiar, Braz } \\
\text { Dias de }\end{array}$ & $\begin{array}{l}\text { Trabalhos da Comissão } \\
\text { Brasileira Demarcadora } \\
\text { de Limites - primeira } \\
\text { divisão - nas fronteiras } \\
\text { da Venezuela e Guianas } \\
\text { Britânicas e Neerlandesas, } \\
\text { de } 1930-40\end{array}$ & $\begin{array}{l}\text { Anais do IX Congresso } \\
\text { Brasileiro de Geografia, } \\
\text { Florianópolis, SC }\end{array}$ & 1940 \\
\hline & Cachuianã & $\begin{array}{l}\text { Vinhaes, } \\
\text { Ernesto }\end{array}$ & $\begin{array}{l}\text { Aventuras de um repórter } \\
\text { na Amazônia }\end{array}$ & $\begin{array}{l}\text { Documentos de nossa } \\
\text { época, 12. 2. ed. Livraria } \\
\text { do Globo, Porto Alegre }\end{array}$ & 1944 \\
\hline
\end{tabular}

1 A versão original deste guia de fontes foi organizada por Adriana Russi em sua tese de 2014, aqui incluída. Para a versão deste Dossiê, as organizadoras incorporaram publicações até 2020. 


\begin{tabular}{|c|c|c|c|c|c|}
\hline $\begin{array}{c}\text { Década/total } \\
\text { trabalhos }\end{array}$ & $\begin{array}{l}\text { Grafia } \\
\text { etnia }\end{array}$ & autor & Título do trabalho & $\begin{array}{l}\text { Outros dados } \\
\text { bibliográficos }\end{array}$ & Ano \\
\hline $\begin{array}{c}1940 \text { a } 1949 \\
3\end{array}$ & Caxuianá & $\begin{array}{l}\text { Faria, João } \\
\text { Barbosa }^{2}\end{array}$ & $\begin{array}{l}\text { Contribuição para o } \\
\text { estudo da arqueologia } \\
\text { pré-histórica do baixo } \\
\text { Amazonas }^{3}\end{array}$ & $\begin{array}{l}\text { Imprensa Nacional, Rio de } \\
\text { Janeiro }\end{array}$ & 1946 \\
\hline \multirow[t]{7}{*}{$\begin{array}{c}1950 \text { a } 1959 \\
18\end{array}$} & Kachúyana & $\begin{array}{l}\text { Gama Mal- } \\
\text { cher, José }\end{array}$ & $\begin{array}{l}\text { Ficha (manuscrita) com } \\
\text { catalogação de etnias }\end{array}$ & $\begin{array}{l}\text { Arquivo Museu do índio } \\
\text { (Rio de Janeiro) }\end{array}$ & 1950 \\
\hline & Caxuianá & $\begin{array}{l}\text { Rondon, } \\
\text { Candido } \\
\text { Mariano da } \\
\text { Silva }\end{array}$ & $\begin{array}{l}\text { Índios do Brasil do norte } \\
\text { do rio Amazonas }\end{array}$ & $\begin{array}{l}\text { Rio de Janeiro: CNPI, } \\
\text { vol. III }\end{array}$ & 1953 \\
\hline & Kachúyana & $\begin{array}{l}\text { Frikel, Gun- } \\
\text { ter Protasio }\end{array}$ & Kamani & $\begin{array}{l}\text { Revista do Museu Paulista, } \\
\text { Nova Série 7: 257-274 }\end{array}$ & 1953 \\
\hline & Caxiuanás & $\begin{array}{l}\text { Cruls, } \\
\text { Gastão }\end{array}$ & $\begin{array}{l}\text { A Amazônia que eu vi - } \\
\text { Óbidos - Tumucumaque }\end{array}$ & $\begin{array}{l}\text { Brasiliana, Série } 5 \text { 113.Cia. } \\
\text { Ed. Nacional; Biblioteca } \\
\text { Pedagógica Brasileira, } \\
\text { São Paulo. }\end{array}$ & 1954 \\
\hline & Kasúyana & Kruse, Albert & $\begin{array}{l}\text { Purá, das Höchste wesen } \\
\text { der Arikéna (Purá, o } \\
\text { ser supremo dos índios } \\
\text { Arikéna) - tradução } \\
\text { Laura Alves }\end{array}$ & $\begin{array}{l}\text { Anthropos } 50 \text { : 404-416. } \\
\text { Switzerland }\end{array}$ & 1955 \\
\hline & Kachuyana & $\begin{array}{l}\text { Frikel, } \\
\text { Frei Protasio }\end{array}$ & $\begin{array}{l}\text { Tradições histórico-len- } \\
\text { dárias dos Kachuyana } \\
\text { e Kahyana (versão } \\
\text { Kachuyana) }\end{array}$ & $\begin{array}{l}\text { Revista do Museu Paulista } \\
9\end{array}$ & 1955 \\
\hline & Kachúyana & $\begin{array}{l}\text { Frikel, } \\
\text { Frei Protasio }\end{array}$ & $\begin{array}{l}\text { Sinais e marcos de } \\
\text { orientação e advertência } \\
\text { indigenas }\end{array}$ & Revista de Antropologia 4 & 1956 \\
\hline
\end{tabular}

2 João Barbosa foi o etnógrafo da Comissão Rondon (expedição Rondon à Serra do Tumucumaque e rio Cuminá 1925-1930), que tinha como objetivo explorar a fronteira do Brasil com a Guiana Holandesa e a "grande família primitiva caraíba ou caribe". A partir da análise de documentos do arquivo do Museu do Índio (RJ), parece que os objetos da coleção etnográfica kaxuyana - a coleção mais antiga de que se tem notícias - podem ter sido coletados durante essa expedição. A coleção estava preservada no Museu Nacional - UFRJ, no Rio de Janeiro, mas foi destruída no trágico incêndio de setembro de 2018 .

3 O Relatório sobre aspectos da cerâmica arqueológica dos rios Trombetas e Jamundá, resultante da expedição Rondon à Serra do Tumucumaque e rio Cuminá - 1925-1930, foi publicado pouco mais de uma década depois como Contribuicão para o estudo da arqueologia pré-histórica do baixo Amazonas. Rio de Janeiro: Imprensa Nacional, 1946 (publicação no 89 da antiga Comissão de Linhas Telegráficas Estratégicas do Mato-Grosso ao Amazonas - "Comissão Rondon"). contém dados do relatório sobre aspectos da cerâmica arqueológica dos rios Trombetas e Jamundá. 


\begin{tabular}{|c|c|c|c|c|c|}
\hline $\begin{array}{l}\text { Década/total } \\
\text { trabalhos }\end{array}$ & $\begin{array}{l}\text { Grafia } \\
\text { etnia }\end{array}$ & autor & Título do trabalho & $\begin{array}{l}\text { Outros dados } \\
\text { bibliográficos }\end{array}$ & Ano \\
\hline \multirow[t]{11}{*}{$\begin{array}{c}1950 \text { a } 1959 \\
18\end{array}$} & Kashuiéna & $\begin{array}{l}\text { Polykrates, } \\
\text { Gottfried }\end{array}$ & $\begin{array}{l}\text { Ein besuch bei Indianern } \\
\text { am Rio Trombetas } \\
\text { (Uma visita aos índios } \\
\text { do rio Trombetas) }\end{array}$ & $\begin{array}{l}\text { Ethnos 3-4: 128-147. Sto- } \\
\text { ckholm, The Ethnografical } \\
\text { Museum of Sweden }\end{array}$ & $1957^{\mathrm{a}}$ \\
\hline & & & $\begin{array}{l}\text { Kurzer bericht ueber } \\
\text { einen besuch bei den } \\
\text { Uarikia'na + Arike'na - } \\
\text { Kashuia'na + Kachu' } \\
\text { yana - Cashue'na - } \\
\text { Kahia'na am rio Cashorro } \\
\text { und rio Trombetas (rela- } \\
\text { tório datilografado) }\end{array}$ & $\begin{array}{l}\text { Arquivo do Museu } \\
\text { Britânico }\end{array}$ & $1957 b$ \\
\hline & & & $\begin{array}{l}\text { Kashuiena'ernes Kurin- } \\
\text { guri-fest - hos indianere i } \\
\text { Amazonas Jungle }\end{array}$ & Vor Viden 223: 449-455 & 1958 \\
\hline & Cahuiana & $\begin{array}{l}\text { Gama } \\
\text { Malcher, } \\
\text { José Maria }\end{array}$ & Tribos da área amazônica & $\begin{array}{l}\text { Belém: Superintendência } \\
\text { do Plano de Valorização } \\
\text { Econômica da Amazônia } \\
\text { (SPVEA) }\end{array}$ & 1958 \\
\hline & Kachúyana & $\begin{array}{l}\text { Frikel, Frei } \\
\text { Protasio }\end{array}$ & $\begin{array}{l}\text { Classificação lingüístico- } \\
\text {-etnológica das tribos indí- } \\
\text { genas do Pará setentrional } \\
\text { e zonas adjacentes }\end{array}$ & $\begin{array}{l}\text { Revista de Antropologia 6: } \\
\text { 113-188 }\end{array}$ & 1958 \\
\hline & Kaxuyana & $\begin{array}{l}\text { Derbyshire, } \\
\text { Desmond }\end{array}$ & $\begin{array}{l}\text { Report on Kaxuyana } \\
\text { (Carib) language }\end{array}$ & $\begin{array}{l}\text { Arquivo Museu Nacional } \\
\text { (Rio de Janeiro) }\end{array}$ & $1958 \mathrm{a}$ \\
\hline & & & $\begin{array}{l}\text { Formulário padrão } \\
\text { Kaxuyana }\end{array}$ & $\begin{array}{l}\text { Arquivo Museu Nacional } \\
\text { (Rio de Janeiro) }\end{array}$ & $1958 b$ \\
\hline & Kashuiéna & $\begin{array}{l}\text { Polykrates, } \\
\text { Gottfried }\end{array}$ & $\begin{array}{l}\text { Zweiter besuch bei } \\
\text { den Indianern am Rio } \\
\text { Trombetas (Segunda } \\
\text { visita aos indígenas no rio } \\
\text { Trombetas) }\end{array}$ & Ethnos 24, 3-4: 208-212 & $1959 a$ \\
\hline & & & $\begin{array}{l}\text { Verdens skabelsehos } \\
\text { Kashuiéna - indianer- } \\
\text { ne - myten om de første } \\
\text { mennesker, som den er } \\
\text { fortalt til }\end{array}$ & Vor viden 261: 29-32 & $1959 b$ \\
\hline & & & $\begin{array}{l}\text { Banandåben. En indiansk } \\
\text { myte om oprindelsen til } \\
\text { en forunderlig rituel skik }\end{array}$ & $\begin{array}{l}\text { Vor Viden 257-258: } \\
705-710\end{array}$ & $1959 \mathrm{c}$ \\
\hline & & & $\begin{array}{l}\text { Krops - og ansigtsmaling } \\
\text { hos nogle sydamerikanske } \\
\text { indianere }\end{array}$ & Vor Viden 262: 33-37 & $1959 d$ \\
\hline
\end{tabular}




\begin{tabular}{|c|c|c|c|c|c|}
\hline $\begin{array}{l}\text { Década/total } \\
\text { trabalhos }\end{array}$ & $\begin{array}{l}\text { Grafia } \\
\text { etnia }\end{array}$ & autor & Título do trabalho & $\begin{array}{l}\text { Outros dados } \\
\text { bibliográficos }\end{array}$ & Ano \\
\hline \multirow[t]{9}{*}{$\begin{array}{c}1960 \text { a } 1969 \\
20\end{array}$} & Cashuiena & $\begin{array}{l}\text { Birket - } \\
\text { Smith, Kaj }\end{array}$ & $?$ & Folk 2 & 1960 \\
\hline & Kaxuiana & $\begin{array}{l}\text { Baldus, } \\
\text { Herbert }\end{array}$ & A lenda do Curare & $\begin{array}{l}\text { In: Estórias e lendas dos } \\
\text { indios }{ }^{4} \text {. Literart, Rio de } \\
\text { Janeiro }\end{array}$ & 1960 \\
\hline & Kachúyana & $\begin{array}{l}\text { Frikel, } \\
\text { Protásio }\end{array}$ & $\begin{array}{l}\text { Os Tiriyó - notas preli- } \\
\text { minares }\end{array}$ & $\begin{array}{l}\text { Boletim do Museu Para- } \\
\text { ense Emilio Goeldi, nova } \\
\text { série - Antropologia } 9\end{array}$ & 1960 \\
\hline & Kashuiéna & $\begin{array}{l}\text { Polykrates, } \\
\text { Gottfried }\end{array}$ & $\begin{array}{l}\text { Einige Holzschmitzereien } \\
\text { der Kashuiéna-indianer } \\
\text { (Alguns trabalhos em ma- } \\
\text { deira dos índios Kaxuya- } \\
\text { na, tradução Marcelo } \\
\text { Victor) }\end{array}$ & Folk 2: 115-120 & 1960 \\
\hline & & & $\begin{array}{l}\text { Beiträge zur: Anthropo- } \\
\text { logie, Ethnografie und } \\
\text { Sprachforschung der } \\
\text { Kashuiéna Indianer sowie } \\
\text { akkulturationserscheinun- } \\
\text { gen (Contribuição para os } \\
\text { estudos antropológicos, } \\
\text { etnográficos e linguísticos } \\
\text { dos índios Kashuiéna } \\
\text { assim como ocorrências } \\
\text { de aculturação, tradução } \\
\text { Sayuri Arakawa) }\end{array}$ & Ethnos 26: 56-74 & 1961 \\
\hline & $\begin{array}{l}\text { Katxhuya- } \\
\text { na }\end{array}$ & $\begin{array}{l}\text { Derbyshire, } \\
\text { Desmond }\end{array}$ & $\begin{array}{l}\text { Notas comparativas sobre } \\
\text { três dialetos Karibe }\end{array}$ & $\begin{array}{l}\text { Boletim do Museu Para- } \\
\text { ense Emilio Goeldi, série } \\
\text { Antropologia } 14\end{array}$ & 1961 \\
\hline & Kachúyana & $\begin{array}{l}\text { Frikel, Frei } \\
\text { Protásio }\end{array}$ & $\begin{array}{l}\text { Mori - a festa do rapé } \\
\text { (indios Kachuyana, rio } \\
\text { Trombetas) }\end{array}$ & $\begin{array}{l}\text { Boletim do Museu Para- } \\
\text { ense Emilio Goeldi, nova } \\
\text { série Antropologia } 12\end{array}$ & 1961a \\
\hline & & & $\begin{array}{l}\text { Fases culturais e acul- } \\
\text { turação intertribal no } \\
\text { Tumucumaque }\end{array}$ & $\begin{array}{l}\text { Boletim do Museu Para- } \\
\text { ense Emilio Goeldi, nova } \\
\text { série Antropologia } 16\end{array}$ & $1961 b$ \\
\hline & Kaxúyana & $\begin{array}{l}\text { Baldus, } \\
\text { Herbert }\end{array}$ & $\begin{array}{l}\text { Os carimbos dos índios } \\
\text { do Brasil }\end{array}$ & $\begin{array}{l}\text { Revista do Museu Paulista, } \\
\text { nova série 13: } 8-75\end{array}$ & $1961-62$ \\
\hline
\end{tabular}

4 O texto referente à lenda do curare dos Kaxuiana, com ilustração de J. Lanzellotti, é uma reprodução da obra de Frikel, P. 1953. Kamani. Revista do Museu Paulista: 267-269. 


\begin{tabular}{|c|c|c|c|c|c|}
\hline $\begin{array}{l}\text { Década/total } \\
\text { trabalhos }\end{array}$ & $\begin{array}{l}\text { Grafia } \\
\text { etnia }\end{array}$ & autor & Título do trabalho & $\begin{array}{l}\text { Outros dados } \\
\text { bibliográficos }\end{array}$ & Ano \\
\hline \multirow[t]{10}{*}{$\begin{array}{c}1960 \text { a } 1969 \\
20\end{array}$} & $\begin{array}{l}\text { Kaschuya- } \\
\text { na }\end{array}$ & $\begin{array}{l}\text { Detering, } \\
\text { Dascha }\end{array}$ & $\begin{array}{l}\text { Flehtwerke und flechttech- } \\
\text { niken der Kaschuyana -in- } \\
\text { dianer nordost- brasiliens } \\
\text { (Trançados e técnicas de } \\
\text { entrançamento dos índios } \\
\text { Kasxhuyana do nordeste } \\
\text { brasileiro). tradução: } \\
\text { Marcelo Moreira }\end{array}$ & $\begin{array}{l}\text { Baessler-Archiv, } \\
\text { Neue Folge 10: 63-104 }\end{array}$ & 1962 \\
\hline & Kashuiéna & $\begin{array}{l}\text { Polykrates, } \\
\text { Gottfried }\end{array}$ & $\begin{array}{l}\text { Beiträge zum verständinis } \\
\text { der Religion und varia- } \\
\text { tionen der materiellen } \\
\text { kulturk der Kashuiéna- } \\
\text {-indianer (Contribuição } \\
\text { para a compreensão da } \\
\text { religião e variações da cul- } \\
\text { tura material dos índios } \\
\text { Kashuiéna). tradução: } \\
\text { Sayuri Arakawa }\end{array}$ & Folk 4: 70-89 & 1962 \\
\hline & & $\begin{array}{l}\text { Frikel, } \\
\text { Protasio }\end{array}$ & $\begin{array}{l}\text { Aculturação intertribal no } \\
\text { Tumucumaque }\end{array}$ & $\begin{array}{l}\text { Actas memórias del XXXV } \\
\text { Congresso Internacional } \\
\text { de Americanistas, México }\end{array}$ & 1962 \\
\hline & Kashuenã & Gillin, John & $\begin{array}{l}\text { Handbook of south } \\
\text { American Indians - tribes } \\
\text { of the Guianas }\end{array}$ & New York 3 & 1963 \\
\hline & Kashuiéna & $\begin{array}{l}\text { Polykrates, } \\
\text { Gottfried }\end{array}$ & $\begin{array}{l}\text { Puragudens Folk } \\
\text { Blandt Amazonlandets } \\
\text { Karibiske indianere }\end{array}$ & $\begin{array}{l}\text { Copenhagen: Hernov } \\
\text { Naturens Verden: 264-286 }\end{array}$ & $\begin{array}{r}1963 \mathrm{a} \\
1963 \mathrm{~b}\end{array}$ \\
\hline & Kachuyána & $\begin{array}{l}\text { Gama } \\
\text { Malcher, José } \\
\text { Maria }\end{array}$ & $\begin{array}{l}\text { Índios - grau de inte- } \\
\text { gração na comunidade } \\
\text { nacional, grupo linguístico, } \\
\text { localização }\end{array}$ & $\begin{array}{l}\text { Rio de Janeiro: CNPI, } \\
\text { nova série } 1\end{array}$ & 1964 \\
\hline & $\begin{array}{l}\text { Kaschúya- } \\
\text { na }\end{array}$ & $\begin{array}{l}\text { Frikel, } \\
\text { Protasio }\end{array}$ & $\begin{array}{l}\text { Das problem der Pianoko- } \\
\text { tó-Tiriyó }\end{array}$ & $\begin{array}{l}\text { Völkerkundliche Adhan- } \\
\text { dlungen, I }\end{array}$ & 1964 \\
\hline & & & $\begin{array}{l}\text { Tradição tribal e arqueo- } \\
\text { logia no Tumucumaque }\end{array}$ & $\begin{array}{l}\text { Revista do Museu } \\
\text { Paulista } 14\end{array}$ & 1965 \\
\hline & & & Os últimos Káhyana & $\begin{array}{l}\text { Revista do Instituto de } \\
\text { Estudos Brasileiros 1, } \\
\text { separata }\end{array}$ & 1966 \\
\hline & & & Relatório de Trabalho & $\begin{array}{l}\text { Acervo documental } \\
\text { MPEG, Belém }\end{array}$ & 1968 \\
\hline
\end{tabular}




\begin{tabular}{|c|c|c|c|c|c|}
\hline $\begin{array}{c}\text { Década/total } \\
\text { trabalhos }\end{array}$ & $\begin{array}{l}\text { Grafia } \\
\text { etnia }\end{array}$ & autor & Título do trabalho & $\begin{array}{l}\text { Outros dados } \\
\text { bibliográficos }\end{array}$ & Ano \\
\hline \multirow[t]{11}{*}{$\begin{array}{c}1970 \text { a } 1979 \\
11\end{array}$} & Kaxúyana & $\begin{array}{l}\text { Frikel, Pro- } \\
\text { tasio }\end{array}$ & $\begin{array}{l}\text { Os Kaxuyana - notas } \\
\text { etno-históricas }\end{array}$ & $\begin{array}{l}\text { Museu Paraense Emilio } \\
\text { Goeldi, Publicações } \\
\text { avulsas } 14\end{array}$ & 1970a \\
\hline & & & $\begin{array}{l}\text { O código de civilidade } \\
\text { Kaxúyana }\end{array}$ & Universitas $6-7$ & $1970 b$ \\
\hline & Kaxuyâna & $\begin{array}{l}\text { Wallace, } \\
\text { Ruth }\end{array}$ & $\begin{array}{l}\text { Notas fonológicas da } \\
\text { língua Kaxuyâna }\end{array}$ & $\begin{array}{l}\text { Boletim do Museu Paraen- } \\
\text { se Emilio Goeldi } 43\end{array}$ & 1970 \\
\hline & Kaxúyana & $\begin{array}{l}\text { Frikel, Pro- } \\
\text { tasio }\end{array}$ & $\begin{array}{l}\text { A mitologia solar e a filo- } \\
\text { sofia de vida dos índios } \\
\text { Kaxúyana }\end{array}$ & $\begin{array}{l}\text { Estudos sobre línguas e } \\
\text { culturas indígenas, Brasí- } \\
\text { lia/DF }\end{array}$ & $1971 \mathrm{a}$ \\
\hline & & & $\begin{array}{l}\text { Dez anos de aculturação } \\
\text { Tiriyó - 1960-1970. } \\
\text { Mudanças e problemas }\end{array}$ & $\begin{array}{l}\text { Museu Paraense Emilio } \\
\text { Goeldi, publicações } \\
\text { avulsas } 16\end{array}$ & $1971 b$ \\
\hline & Kaxúyana & $\begin{array}{l}\text { Frikel, Prota- } \\
\text { sio; Cortez, } \\
\text { Roberto }\end{array}$ & $\begin{array}{l}\text { Elementos demográficos } \\
\text { do alto Paru de Oeste, } \\
\text { Tumucumaque Brasileiro } \\
\text { (índios Ewarhoyána, } \\
\text { Kaxúyana e Tiriyó) }\end{array}$ & $\begin{array}{l}\text { Museu Paraense Emílio } \\
\text { Goeldi, publicações avulsas }\end{array}$ & 1972 \\
\hline & Kaxuyâna & $\begin{array}{l}\text { Paula, Ruth } \\
\text { wallace de } \\
\text { Garcia }\end{array}$ & $\begin{array}{l}\text { Harmonia vocálica nos } \\
\text { afixos de posse na língua } \\
\text { Kaxuyâna }\end{array}$ & $\begin{array}{l}\text { Revista Brasileira de Lin- } \\
\text { guística 3: } 42-50\end{array}$ & 1976 \\
\hline & Kaxúyana & $\begin{array}{l}\text { Cortez, } \\
\text { Roberto }\end{array}$ & $\begin{array}{l}\text { O diaconato indígena: } \\
\text { articulação étnica no recôn- } \\
\text { cavo do Tumucumaque } \\
\text { Brasileiro }\end{array}$ & $\begin{array}{l}\text { Dissertação, UFRJ/MN, } \\
\text { Rio de Janeiro }\end{array}$ & 1977 \\
\hline & Kaxuyâna & $\begin{array}{l}\text { Paula, Ruth } \\
\text { wallace de } \\
\text { Garcia }\end{array}$ & $\begin{array}{l}\text { Lingua kaxuyâna: fono- } \\
\text { logia segmental e afixos } \\
\text { nominais }\end{array}$ & $\begin{array}{l}\text { Dissertação, Rio de Janei- } \\
\text { ro, MN/UFRJ }\end{array}$ & 1977 \\
\hline & Kaxúyana & $\begin{array}{l}\text { Andrade, } \\
\text { Carlos } \\
\text { Drummond } \\
\text { de }\end{array}$ & $\begin{array}{l}\text { O Kaxúyana, } \\
\text { esse bem-educado }\end{array}$ & $\begin{array}{l}\text { Jornal do Brasil, } \\
\text { 24/10/1978, p. } 5\end{array}$ & 1978 \\
\hline & Kachuyana & $\begin{array}{l}\text { Van Velthen, } \\
\text { Lucia Hussak }\end{array}$ & $\begin{array}{l}\text { Referências sobre o } \\
\text { Parque Indígena do } \\
\text { Tumucumaque }\end{array}$ & CEDI & 1979 \\
\hline $\begin{array}{c}1980 \text { a } 1989 \\
10\end{array}$ & Kachuyâna & $\begin{array}{l}\text { Van Velthen, } \\
\text { Lucia Hussak }\end{array}$ & $\begin{array}{l}\text { O parque indígena de } \\
\text { Tumucumaque... }\end{array}$ & $\begin{array}{l}\text { Boletim do Museu } \\
\text { Paraense Emilio Goeldi, } \\
\text { Antropologia } 76\end{array}$ & 1980 \\
\hline
\end{tabular}




\begin{tabular}{|c|c|c|c|c|c|}
\hline $\begin{array}{l}\text { Década/total } \\
\text { trabalhos }\end{array}$ & $\begin{array}{l}\text { Grafia } \\
\text { etnia }\end{array}$ & autor & Título do trabalho & $\begin{array}{l}\text { Outros dados } \\
\text { bibliográficos }\end{array}$ & Ano \\
\hline \multirow[t]{9}{*}{$\begin{array}{c}1980 \text { a } 1989 \\
10\end{array}$} & Kaxúyana & $\begin{array}{l}\text { Almeida, } \\
\text { Maria da } \\
\text { Penha C. }\end{array}$ & $\begin{array}{l}\text { Relatório referente ao } \\
\text { projeto de construção da } \\
\text { hidrelétrica de Cachoeira } \\
\text { Porteira (Trombetas) }\end{array}$ & $\begin{array}{l}\text { Arquivo ISA - Processo } \\
\text { Funai 3115/81 }\end{array}$ & $1981 \mathrm{a}$ \\
\hline & & & $\begin{array}{l}\text { Relatório eleição e delimi- } \\
\text { tação dos PIS Nhamundá } \\
\text { e Mapuera }\end{array}$ & $\begin{array}{l}\text { Arquivo ISA - Processo } \\
\text { Funai 2989/80 }\end{array}$ & $1981 b$ \\
\hline & Kaxuiâna & $\begin{array}{l}\text { Rodrigues, } \\
\text { Ivelise; } \\
\text { Figueiredo, } \\
\text { Napoleão }\end{array}$ & $\begin{array}{l}\text { Catálogo das coleções } \\
\text { etnográficas do Museu } \\
\text { Paraense Emílio Goeldi } \\
\text { e Universidade Federal } \\
\text { do Pará }\end{array}$ & $\begin{array}{l}\text { Instituto Nacional de } \\
\text { Pesquisas da Amazônia; } \\
\text { Museu Paraense Emilio } \\
\text { Goeldi, Belém }\end{array}$ & 1982 \\
\hline & Kaxuyana & $?$ & $\begin{array}{l}\text { Termo de convênio entre } \\
\text { Missão Tiriyó e Funai }\end{array}$ & & 1982 \\
\hline & & Funai & $\begin{array}{l}\text { Trata da posse área aos } \\
\text { Hixkaryana, Kaxuyana, } \\
\text { Wai-wai, Katuena, } \\
\text { Mamayana, Xirieu }\end{array}$ & $\begin{array}{l}\text { Portaria n. }{ }^{\circ} 1.465 . \text { de } \\
21 \text { de novembro de } 1982\end{array}$ & 1982 \\
\hline & Kaxuyâna & $\begin{array}{l}\text { Paula, Ruth } \\
\text { wallace de } \\
\text { Garcia }\end{array}$ & $\begin{array}{l}\text { Comparação de afixos de } \\
\text { posse em línguas Karib }\end{array}$ & $\begin{array}{l}\text { Boletim do Museu do } \\
\text { índio, série Linguística } 2\end{array}$ & 1983 \\
\hline & Kaxuyana & $\begin{array}{l}\text { Ricardo, } \\
\text { Carlos Alber- } \\
\text { to; Gallois, } \\
\text { Dominique }\end{array}$ & $\begin{array}{l}\text { Povos Indigenas do Brasil - } \\
\text { verbete Kaxuyana }\end{array}$ & $\begin{array}{l}\text { Vol. } 3 \text { - Amapá e norte do } \\
\text { Pará. Cedi, São Paulo }\end{array}$ & 1983 \\
\hline & Kaxúyana & $\begin{array}{l}\text { Torres, Cons- } \\
\text { tantino }\end{array}$ & $\begin{array}{l}\text { Tabletas para alucinó- } \\
\text { genos en Sudamérica: } \\
\text { tipologia, distribucion y } \\
\text { rutas de difusion }\end{array}$ & $\begin{array}{l}\text { Boletin Del Museo Chileno } \\
\text { de Arte Precolombino } 1\end{array}$ & 1986 \\
\hline & Kaxuyana & $\begin{array}{l}\text { Meirelles, J.; } \\
\text { Leoni, Rena- } \\
\text { to; Oliveira } \\
\text { Filho, J. }\end{array}$ & $\begin{array}{l}\text { Análise de área indígena } \\
\text { Nhamundá/Mapuera }\end{array}$ & $\begin{array}{l}\text { Parecer n. }{ }^{\circ} 88 \text { do GT } \\
\text { Funai }\end{array}$ & 1986 \\
\hline $\begin{array}{c}1990 \text { a } 1999 \\
1\end{array}$ & Kaxuyana & $\begin{array}{l}\text { Pereira, } \\
\text { Maria Denise } \\
\text { Farjado }\end{array}$ & $\begin{array}{l}\text { Resgatando a escola junto } \\
\text { com os Tiriyó e Kaxuyana }\end{array}$ & NHII/USP & 1998 \\
\hline \multirow[t]{2}{*}{$\begin{array}{c}2000 \text { a } 2009 \\
13\end{array}$} & Kaxuyana & $\begin{array}{l}\text { Pereira, } \\
\text { Maria Denise } \\
\text { Farjado }\end{array}$ & $\begin{array}{l}\text { Parque Indígena do } \\
\text { Tumucumaque: novos } \\
\text { parceiros, novos desafios. } \\
\text { PIB - Povos Indígenas do } \\
\text { Brasil (1996-2000) }\end{array}$ & $\begin{array}{l}\text { v. 3. Amapá e norte do } \\
\text { Pará. ISA, São Paulo }\end{array}$ & 2001 \\
\hline & Katxuyana & $\begin{array}{l}\text { Grupioni, } \\
\text { Denise }\end{array}$ & $\begin{array}{l}\text { Povos recuperam antigos } \\
\text { locais de moradia } \\
\text { PIB - Povos Indígenas do } \\
\text { Brasil (2001-2005) }\end{array}$ & ISA, São Paulo & 2006 \\
\hline
\end{tabular}




\begin{tabular}{|c|c|c|c|c|c|}
\hline $\begin{array}{c}\text { Década/total } \\
\text { trabalhos }\end{array}$ & $\begin{array}{l}\text { Grafia } \\
\text { etnia }\end{array}$ & autor & Título do trabalho & $\begin{array}{l}\text { Outros dados } \\
\text { bibliográficos }\end{array}$ & Ano \\
\hline \multirow[t]{11}{*}{$\begin{array}{c}2000 \text { a } 2009 \\
13\end{array}$} & Kaxuyana & $\begin{array}{l}\text { Bessa, Juce- } \\
\text { lino }\end{array}$ & Informação no. 01 & Funai & 2003 \\
\hline & Katxuyana & $\begin{array}{l}\text { Gallois, } \\
\text { Dominique; } \\
\text { Grupioni, } \\
\text { Denise }\end{array}$ & $\begin{array}{l}\text { Povos indígenas no Ama- } \\
\text { pá e norte do Pará: quem } \\
\text { são, onde estão, quantos } \\
\text { são, como vivem e o que } \\
\text { pensam? }\end{array}$ & $\begin{array}{l}\text { Iepé/NHII/USP, São } \\
\text { Paulo }\end{array}$ & 2003 \\
\hline & Kaxuyana & $\begin{array}{l}\text { Representan- } \\
\text { tes do Povo } \\
\text { Kaxuyana }\end{array}$ & $\begin{array}{l}\text { Retorno ao território } \\
\text { tradicional }\end{array}$ & Carta à Deid/Funai & 2003 \\
\hline & Kaxuyana & $\begin{array}{l}\text { Miranda, } \\
\text { Marlui }\end{array}$ & $\begin{array}{l}\text { Ponte entre povos: a mú- } \\
\text { sica dos índios e a música } \\
\text { erudita no Amapá }\end{array}$ & Brasil & 2005 \\
\hline & $\begin{array}{l}\text { Katxuyana, } \\
\text { Kaxuyana }\end{array}$ & $\begin{array}{l}\text { Gallois, } \\
\text { Dominique }\end{array}$ & $\begin{array}{l}\text { Redes de relações nas } \\
\text { Guianas }\end{array}$ & Humanitas, São Paulo & 2005 \\
\hline & Katxuyana & Meira, Sergio & $\begin{array}{l}\text { A família lingüística } \\
\text { Caribe (Karib) }\end{array}$ & $\begin{array}{l}\text { Revista de Estudos e } \\
\text { Pesquisas 3: } 157174\end{array}$ & 2006 \\
\hline & Kaxuyana & $\begin{array}{l}\text { Gongora, } \\
\text { Majoi }\end{array}$ & $\begin{array}{l}\text { No rastro da cobra-gran- } \\
\text { de: variações e sociocos- } \\
\text { mológicas - a questão da } \\
\text { diferença na região das } \\
\text { Guianas }\end{array}$ & $\begin{array}{l}\text { Dissertação, Universidade } \\
\text { de São Paulo, São Paulo }\end{array}$ & 2007 \\
\hline & & $\begin{array}{l}\text { Queiroz, Ru- } \\
\text { ben Caixeta } \\
\text { de }\end{array}$ & $\begin{array}{l}\text { Trombetas-Mapuera: } \\
\text { território indígena }\end{array}$ & PPTAL; Funai, Brasilia/DF & 2008 \\
\hline & & Apitikatxi & $\begin{array}{l}\text { Tamiriki: construindo } \\
\text { uma casa, reconstruindo } \\
\text { uma cultura }\end{array}$ & $\begin{array}{l}\text { Projeto submetido ao Prê- } \\
\text { mio Culturas Indigenas, } \\
\text { edição } 2007\end{array}$ & 2008 \\
\hline & Katxuyana & Sesc Sp & $\begin{array}{l}\text { Prêmio Culturas Indí- } \\
\text { genas - Edição Xicão } \\
\text { Xukuru }\end{array}$ & sesc, São Paulo & 2008 \\
\hline & Kaxuyana & $\begin{array}{l}\text { Grupioni, } \\
\text { Denise }\end{array}$ & $\begin{array}{l}\text { Arte visual dos povos } \\
\text { Tiriyó e Kaxuyana }\end{array}$ & Iepé, São Paulo & 2009 \\
\hline \multirow[t]{2}{*}{$\begin{array}{c}2010 \text { a } 2020 \\
17\end{array}$} & Kaxuyana & $\begin{array}{l}\text { Girardi, } \\
\text { Luisa }\end{array}$ & $\begin{array}{l}\text { A terra e a gente: conside- } \\
\text { rações sobre a transitivida- } \\
\text { de em uma demarcação }\end{array}$ & $\begin{array}{l}\text { 27a reunião Brasileira de } \\
\text { Antropologia, Belém }\end{array}$ & 2010a \\
\hline & & & $\begin{array}{l}\text { Cosmopolítica Kaxuyana: } \\
\text { notas sobre uma demarca- } \\
\text { ção de terra indígena }\end{array}$ & Anpocs & $2010 \mathrm{~b}$ \\
\hline
\end{tabular}




\begin{tabular}{|c|c|c|c|c|c|}
\hline $\begin{array}{l}\text { Década/total } \\
\text { trabalhos }\end{array}$ & $\begin{array}{l}\text { Grafia } \\
\text { etnia }\end{array}$ & autor & Título do trabalho & $\begin{array}{l}\text { Outros dados } \\
\text { bibliográficos }\end{array}$ & Ano \\
\hline \multirow[t]{10}{*}{$\begin{array}{c}2010 \text { a } 2020 \\
17\end{array}$} & Kaxuyana & $\begin{array}{l}\text { Programa de } \\
\text { Formação de } \\
\text { Professores- } \\
\text {-Pesquisado- } \\
\text { res Tiriyó e } \\
\text { Kaxuyana do } \\
\text { Iepé }\end{array}$ & $\begin{array}{l}\text { Aprendendo o portu- } \\
\text { guês nas escolas Tiriyó e } \\
\text { Kaxuyana }\end{array}$ & $\begin{array}{l}\text { Imprensa Oficial; iepé, } \\
\text { São Paulo }\end{array}$ & $2010 \mathrm{a}$ \\
\hline & & $\begin{array}{l}\text { Programa de } \\
\text { Formação de } \\
\text { Professores- } \\
\text {-Pesquisado- } \\
\text { res Tiriyó e } \\
\text { Kaxuyana do } \\
\text { Iepé }\end{array}$ & $\begin{array}{l}\text { Praticando o português } \\
\text { nas escolas Tiriyó e } \\
\text { Kaxuyana }\end{array}$ & $\begin{array}{l}\text { Imprensa Oficial; Iepé, } \\
\text { São Paulo }\end{array}$ & $2010 b$ \\
\hline & & $\begin{array}{l}\text { Grupioni, } \\
\text { Denise }\end{array}$ & $\begin{array}{l}\text { Kaxuyana: de volta à sua } \\
\text { terra de origem }\end{array}$ & ISA/Iepé, São Paulo & 2010 \\
\hline & & $\begin{array}{l}\text { Troncarelli, } \\
\text { Maria Cristi- } \\
\text { na (Org.) }\end{array}$ & $\begin{array}{l}\text { Livro de alfabetização na } \\
\text { língua kaxuyana }\end{array}$ & ISA/Iepé, São Paulo & 2010 \\
\hline & & $\begin{array}{l}\text { Grupioni, } \\
\text { Denise }\end{array}$ & verbete Kaxuyana & $\begin{array}{l}\text { In: Ricardo, Beto; Ricardo, } \\
\text { Fany. Povos Indigenas do } \\
\text { Brasil (2006-2010). ISA, } \\
\text { São Paulo }\end{array}$ & 2011 \\
\hline & & $\begin{array}{l}\text { Girardi, } \\
\text { Luisa }\end{array}$ & $\begin{array}{l}\text { Gente do Kaxuru: } \\
\text { mistura e transformação } \\
\text { entre um povo indigena } \\
\text { Karib-Guianense }\end{array}$ & $\begin{array}{l}\text { Dissertação, Universidade } \\
\text { Federal da Minas Gerais, } \\
\text { Belo Horizonte }\end{array}$ & 2011 \\
\hline & & $\begin{array}{l}\text { Russi, } \\
\text { Adriana }\end{array}$ & $\begin{array}{l}\text { Os Kaxuyana e a tamiriki: } \\
\text { memória e identidade }\end{array}$ & $\begin{array}{l}\text { XXXIII Convegno Interna- } \\
\text { zionale di Americanistica, } \\
\text { Italia }\end{array}$ & 2011 \\
\hline & & $\begin{array}{l}\text { Queiroz, Ru- } \\
\text { ben Caixeta } \\
\text { de; Gonçal- } \\
\text { ves Girardi, } \\
\text { Luisa }\end{array}$ & $\begin{array}{l}\text { Dispersão e concentração } \\
\text { indigena nas fronteiras } \\
\text { das Guianas: análise do } \\
\text { caso Kaxuyana }\end{array}$ & $\begin{array}{l}\text { Revista Brasileira do } \\
\text { Caribe 13: } 15-42\end{array}$ & 2012 \\
\hline & & $\begin{array}{l}\text { Russi, Adria- } \\
\text { na; Abreu, } \\
\text { Regina }\end{array}$ & $\begin{array}{l}\text { Coleções etnográficas } \\
\text { europeias - memória e di- } \\
\text { álogo a partir de artefatos } \\
\text { dos ameríndios Kaxuyana }\end{array}$ & $\begin{array}{l}\text { IV REA e XIII ABANNE, } \\
\text { Fortaleza }\end{array}$ & 2013 \\
\hline & & $\begin{array}{l}\text { Russi, } \\
\text { Adriana }\end{array}$ & $\begin{array}{l}\text { I Kaxuyana e la casa } \\
\text { tamiriki: un processo di } \\
\text { patrimonializzazione }\end{array}$ & Etnografie Amazzoniche 3 & 2013 \\
\hline
\end{tabular}




\begin{tabular}{|c|c|c|c|c|c|}
\hline $\begin{array}{c}\text { Década/total } \\
\text { trabalhos }\end{array}$ & $\begin{array}{l}\text { Grafia } \\
\text { etnia }\end{array}$ & autor & Título do trabalho & $\begin{array}{l}\text { Outros dados } \\
\text { bibliográficos }\end{array}$ & Ano \\
\hline \multirow[t]{6}{*}{$\begin{array}{c}2010 \text { a } 2020 \\
17\end{array}$} & Kaxuyana & $\begin{array}{l}\text { Mello, Adria- } \\
\text { na Russ T. }\end{array}$ & $\begin{array}{l}\text { Tamiriki, pata yotono } \\
\text { kwama: a reconstrução } \\
\text { de uma casa, a valori- } \\
\text { zação de uma cultura } \\
\text { e o protagonismo dos } \\
\text { ameríndios Kaxuyana às } \\
\text { margens do rio Cachorro } \\
\text { (Oriximiná/PA) }\end{array}$ & $\begin{array}{l}\text { Tese, Universidade Fede- } \\
\text { ral do Estado do Rio de } \\
\text { Janeiro, Rio de Janeiro }\end{array}$ & 2014 \\
\hline & Katxuyana & $\begin{array}{l}\text { Kieffer-Døssing, } \\
\text { Astrid }\end{array}$ & $\begin{array}{l}\text { Re-assembling the } \\
\text { Katxuyana collections: an } \\
\text { analusis of past, present } \\
\text { and possible futures of } \\
\text { the Katxuyana collections } \\
\text { as assemblages }\end{array}$ & Dissertação, Aarhus & 2016 \\
\hline & Kaxuyana & $\begin{array}{l}\text { Hoffmann, } \\
\text { Beatrix. }\end{array}$ & $\begin{array}{l}\text { Ambivalencias: } \\
\text { Günther Protásio Frikel } \\
\text { (1912-1974), misionero } \\
\text { y antropólogo amigo de } \\
\text { indígenas brasileños y } \\
\text { ayudante de intereses } \\
\text { gubernamentales }\end{array}$ & $\begin{array}{l}\text { Revista de historia de las } \\
\text { ciencias y las humanida- } \\
\text { des 1: 124-149 }\end{array}$ & 2017 \\
\hline & Katxuyana & $\begin{array}{l}\text { Russi, Adria- } \\
\text { na; Abreu, } \\
\text { Regina }\end{array}$ & $\begin{array}{l}\text { A reconstrução da casa } \\
\text { tamiriki: protagonismo e } \\
\text { valorização cultural entre } \\
\text { os ameríndios Katxuyana }\end{array}$ & $\begin{array}{l}\text { In: Abreu, Regina; Freire, } \\
\text { José Ribamar (Org.). } \\
\text { Memórias e patrimônios } \\
\text { indigenas: conquistas e } \\
\text { desafios. Curitiba, CRV, } \\
\text { 141-158 }\end{array}$ & 2018 \\
\hline & & $\begin{array}{l}\text { Russi, Adriana; } \\
\text { Kieffer-Døs- } \\
\text { sing, Astrid }\end{array}$ & $\begin{array}{l}\text { Museums and indigenous } \\
\text { memories: the collections of } \\
\text { the Katxuyana and the con- } \\
\text { temporaneity of musealized } \\
\text { material culture }\end{array}$ & $\begin{array}{l}\text { Museum and Society 17: } \\
494-509\end{array}$ & 2019 \\
\hline & Katxuyana & $\begin{array}{l}\text { Russi, } \\
\text { Adriana }\end{array}$ & $\begin{array}{l}\text { Os Katxuyana, suas } \\
\text { memórias e a defesa de } \\
\text { seus direitos: dos objetos } \\
\text { musealizados à revitaliza- } \\
\text { ção cultural. }\end{array}$ & $\begin{array}{l}\text { In: Oliveira, Maria Amália } \\
\text { Silva Alves et al. (Coord.). } \\
\text { Ensaios sobre Memória. } \\
\text { Escola Superior de Edu- } \\
\text { cação e Ciências Sociais, } \\
\text { Leiria, 10-36 }\end{array}$ & 2020 \\
\hline
\end{tabular}

